\title{
Reflection on MOOCs in the Special Period of Anti-coronavirus*
}

\author{
Yuefang Sun \\ Foreign Language Department, Jining Medical College, Jining, Shandong 27200, China
}

\begin{abstract}
MOOC has been the main application platform of online education, and the higher education in our country has been greatly promoted with the popularization of MOOC in colleges and universities and with the sharing of the high quality teaching resources. The outbreak of COVID-19 in China makes online teaching be the focus of attention again, which has boosted the development of MOOC in China. The author of this essay has conducted a survey of the present situation of MOOC in academically average colleges in China, among which Jining Medical college was set as an example. The present situation of MOOC has been analyzed in this essay, while data has been collected through questionnaires and has been analyzed with scientific methods, the result of which will be of some reference value to the network resources construction of teaching platform like MOOC in China.
\end{abstract}

Index Terms-MOOC, COVID-19, reference value

\section{INTRODUCTION}

\section{A. The Concept of MOOC}

MOOC (Massive Open Online Course), originating from OER (Open Educational Resources) and Connectives, is the result of the combination between education and network technology, an emerging online educational form which is greatly different from the traditional teaching mode. Up to now, there have been millions of registers of MOOC platforms since Canadian scholars Siemens and Downes started the first MOOC Connectives and Connective knowledge in 2008. According to the assessment report of the investigation into the online education from the academic year of 2002-2003 to the academic year of 2012-2013 by American Sloan Consortium, the number of registers and the recognition of online education in American higher education have shown the trend of sustainable and steady development. The combination of higher education and network technology seemed to be irreversible, and then the biggest and most famous MOOC platforms came into being in America: Audacity by Professor Stevens of Stanford University and his partner, edX by Harvard and MIT, and Coursera by Professor Keller and Professor Wu Edna of Stanford University. Thus, 2012 is called the first year of MOOC.

\section{B. MOOCs and China}

Much later though MOOCs in China got started than the developed countries in Europe and America, we have done much preparation for online education of colleges and universities. Our government has made a series of policies to support online education since 2000. In educational reform, our government has given the priority to the overall development of education by combining information technology with educational innovation to let more excellent educational resources be shared and to modernize education. In fact, we also started MOOCs in 2012---In October, 2012, people with more experience of Internet education company set up the first MOOC platform. 2013 has witnessed MOOCs spring up in China on a large scale. Then some top Chinese universities joined edX and Coursera, such as, Tsinghua University, Beijing University, Fudan University, Shanghai Jiao Tong University, etc. According to data from Coursera, in 2013 there were 130 thousand Chinese registers on Coursera, ranking ninth in the world, while 650 thousand in 2014 with rapider growth than most of other countries. In October, 2013, Tsinghua University set up the first Chinese MOOC platform called XuetangX, so 2013 is the first MOOC year of China. In April,2014, Shanghai Jiao Tong University developed and released online its Chinese MOOC platform with ten courses for the first time. In May, 2014, Icourse, another online education platform developed by Beijing University, mingled MOOC with their own courses under the help of flipped classroom with over 1000 thousand registers on its 200th day online. Zhihuishu, the biggest MOOCs platform in China now and developed by Shanghai Zhuo Yue Digital Technology Co. , Ltd, helps different universities share teaching resources, set up credit-recognition system, and enable students to go on with cross-institutional studies. Over 17 million students have completed their cross-institutional studies. XuetangX, Icourse, and Zhihuishu are three online education platforms, which have drawn a great attention of our Ministry of Education and are popular among learners and educators. As a new mode of online education, MOOC is not only a challenge for our traditional higher education but also a driving force for higher educational advance.

\footnotetext{
* This paper is part of results of Philosophy and Social Science Planning Project granted by Jining, Shandong Province (20JSGX058).
} 


\section{The Present Situation OF MOOCs In ChinA}

At the end of 2019, there was an outbreak of COVID-19 in Wuhan, China, which needed people to stay isolated from others to stop the further spreading of the dreadful virus. Online education went on nationwide, and MOOC platforms have played significant roles in both higher education and elementary education, especially in the key period of anti-corona virus. MOOC known for its free of charge, openness, high-efficiency, and convenience, is appreciated by most of learners all over the world, while MOOC combines the same basic principles with local features of different countries according to their own situation. At present, MOOC in China has presented a series of characteristics.

1. MOOCs are mostly applied to higher education, but colleges in different cities differ a lot from each other. Generally speaking, the bigger the cities are, the more colleges there are likely to carry out MOOCs, and the more attention MOOC is paid to. Reasons are mostly due to the fact that colleges and universities in bigger cities are more likely to launch MOOC with more attention from their leaders, richer resources of teaching staff, better sources of students with strong autonomy, and more access to advanced information technology.

2. In contrast to the fact that MOOC platforms are used extensively and successfully in primary education in foreign countries, MOOC platform is now only in some parts of our country to get a trial (Chen Yonggeng and Zhong Man, 2016). In China, there are few MOOCs in basic education. Here "basic education" refers to junior secondary education and primary education. Theoretically speaking, MOOCs can help to promote the development of education and the fairness in education, but there are still more difficulties in applying them to basic education.

(1) There are few MOOC resources of basic education, most of which are developed in higher education. Strictly speaking, MOOC is a way of learning for adults, a reform in higher education. MOOC is mainly aiming at college students, so it has become mature both in resources and curriculums in higher education, and both research and application of MOOC in China always take place in higher education, too. There is little research and application of MOOC in basic education.

(2) Self-control of learners is one of premises to complete MOOCs successfully. In basic education, the audience is young with poor autonomy and self-control. In terms of the contents conveyed by MOOCs, MOOCs are suitable to any kind of education, but when it comes to the target audience, different from college students, students of basic education are not autonomic enough to attend MOOCs alone. Thus, the application of MOOCs in basic education relies more on substantial collaboration between teachers and parents. In the process of learning, students depend much on the information offered by their teachers and parents, which makes it harder for them to attend MOOCs consciously. Without teachers' proper guidance of learning or parents' supervision, MOOCs learning of students in basic education can't achieve the expected results.

(3) At the stage of basic education, it is still the exam-oriented education, so exam results are still the most important thing to evaluate both teaching and learning efficiency. According to a survey online, some of parents don't approve of MOOCs in basic education, because they worry about the bad effect MOOCs may bring to their children's eyes for long staring at computer screen, and many of them fear for the low learning efficiency when both of parents have to go to work and leave their children study online at home alone.

(4) As is known, it often takes a long time for teachers to prepare for a MOOC, especially the recording part, and since the audience is teenagers or the younger who always distract their attention easily from things they think less attractive, not only the contents but also the representation should be paid much more attention, which definitely will exhaust makers. Generally speaking, curriculums in basic education are much easier and less than that in higher education, so most of teachers would like to undertake their teaching activities in class.

3. The learning effectiveness and efficiency of MOOCs in humanities are not as good as that in science and engineering. Just as the tenured Professor Hans Martin Sars ever said that MOOCs were good enough for chemistry and math, but not good enough for humanities, such as, bioethics, philosophy, etc, which are more complicated and need to be explained from multi-dimensional perspective (Tang Ying, 2015). Humanities is a special subject group about the relationship between people, mainly focusing on relief, emotion, mentality, morality, aesthetics, value, etc, which are relevant to human beings or individual spirits. Different from science and engineering, humanities consist of lots of concepts and theories which should be understood with emotion and reflection, and should be conveyed through communications between learners with empathy. At present, most of MOOCs have been made with fancy recording forms, without which there is the thing left more like the traditional teaching mode-more monologues of teachers, less interaction between teachers and students.

\section{CASE ANALYSIS}

\section{A. Objects of Study}

The author of this essay chose the MOOCs in Jining Medical College as a case analysis. Ninety teachers of three different age groups(25 35, 36 45, 46 55) and two hundred college students from four different grades(freshman, sophomore, junior, senior) with fifty students in each group were chosen randomly to be the objects of this study. By the way, Zhihuishu (mentioned in Part I ) has been used as the online education platform in Jining Medical College.

\section{B. The Research Method}


The research was conducted by means of questionnaire survey, mathematical statistics, and interview. The author interviewed ninety teachers about the usage of MOOCs, while two hundred college students were given two questionnaires: one is about factors affecting their choice of MOOCs, which were taken back on the spot with 3 invalid, while the other is about the factors affecting their MOOC learning, among which 5 are invalid.

\section{Data Processing}

In this research the questionnaires with Unicode were analyzed with SPSS23.0, and the statistical description of the count data is performed with frequency and percentage.

\section{The Results}

1. The results of the interviews

The author, in spare time, has interviewed ninety teachers of three different age groups $(25 \sim 35,36 \sim 45$, 46 55), with 15 females and 15 males in each group. They were asked about the usage of MOOC, and answers have been shown in Table I

TABLE I

THE RESULTS OF THE USAGE OF MOOC IN DIFFERENT AGE GROUPS

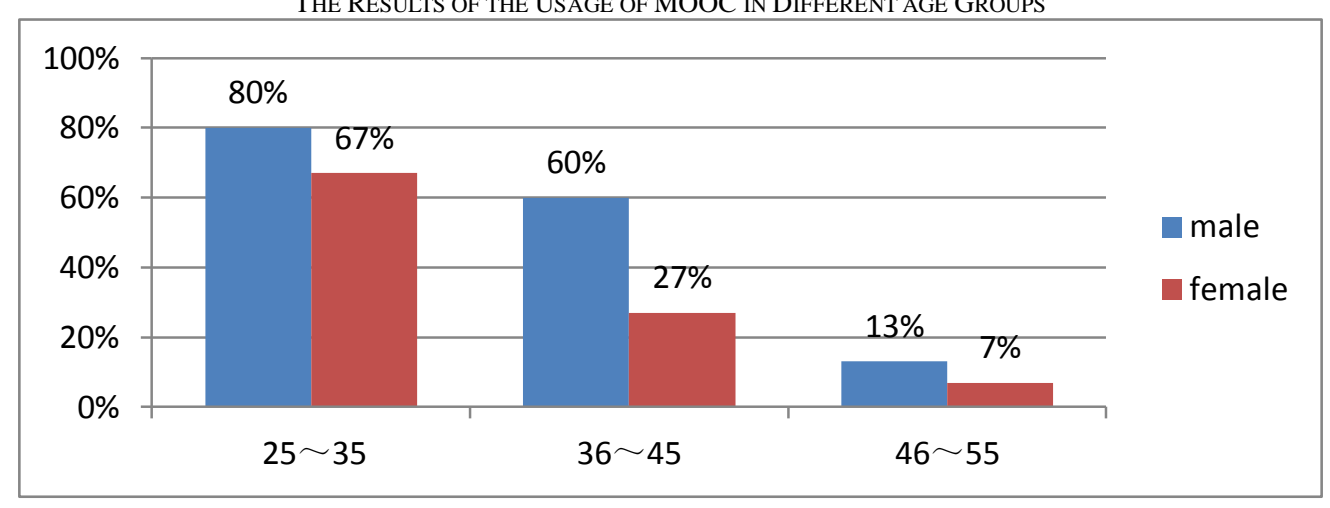

From Table I, we can see: In the age group of 25 35, most of them would like to conduct MOOCs, with 10 out of 15 females and 12out of 15 males, which is may due to the fact that they are young and ambitious enough to like to learn something new, and that most of them are single or newly-married who can have more time spent on work; In the age group of 36 45, there is a decline of the usage of MOOCs in male teachers, with a sharp downturn in female teachers, and the main reason is that people of this age always have a family with children to tend or to tutor, especially women of this age in China who are usually given the main responsibility for taking care of their children and their family, as a result of which they spend less time in exploring new things and they just want things to go on easily and smoothly. Conducting MOOC will consume much more time than traditional teaching, so most of them would like to adopt the traditional ways in class; In the age group of 46 55, few of them will undertake MOOC, because man of this age has little passion for change, and they firmly believe that the accumulated teaching experience instead of their teaching mode is the most precious thing for their work as well as for students.

2. The Results of questionnaires

Two hundred college students in three different grades (freshman, sophomore, junior, senior) were chosen randomly to answer the questions about the reasons for choosing or quitting a MOOC. They were people who could almost speak for all undergraduates of Jining Medical College, because they were the people who were going to have or were having or had had a MOOC or MOOCs. The questions were designed into multiple-choice questions. Actually, the question about the reasons for choosing a MOOC is the question about their motivations for a MOOC. The results of questionnaires have been illustrated in Table II and Table III.

TABLE II

MOTIVATIONS FOR MOOCS $\mathrm{N}(\%)$

\begin{tabular}{lllll}
\multicolumn{7}{c}{ MOTIVATIONS FOR MOOCS } & $\mathrm{N}(\%)$ & & \\
\hline Motivations & freshman & sophomore & junior & senior \\
\hline Obtain more things outside curriculums & $4(8)$ & $17(34)$ & $25(50)$ & $39(78)$ \\
Supplement what 've learned in class & $41(82)$ & $30(60)$ & $24(48)$ & $25(50)$ \\
Learn top-quality courses at close quarters & $3(6)$ & $11(22)$ & $23(46)$ & $41(82)$ \\
Like the learning way with open communications & $11(22)$ & $14(28)$ & $15(30)$ & $7(14)$ \\
Attracted by the brand awareness of MOOC & $5(10)$ & $20(40)$ & $29(58)$ & $17(34)$ \\
Gain more credits or qualifications & $4(8)$ & $15(30)$ & $27(54)$ & $40(80)$ \\
Be curious about the way of learning & $13(26)$ & $0(0)$ & $0(0)$ & $0(0)$ \\
Follow suit & $9(18)$ & $0(0)$ & $0(0)$ & $0(0)$ \\
\hline
\end{tabular}

From Table II, it can be concluded that in whole college students have known what MOOCs are from the beginning of their college life, while the reasons for MOOCs are different from each other. In China, for various reasons, MOOCs seldom take place before colleges and universities, so to the freshmen, they have learned of MOOCs but seldom 
experienced it. Thus, 13 out of 50 of them choose MOOCs just for curiosity and nearly 18 percent of them follow suit, while most of them choose MOOCs for supplementing what have learned in class because there is a great difference of the way of leaning between high school and college, which requires them to learn more outside the class. At the stage of being s sophomore or a junior when they have got used to college life and when some of them come to know what they really want to achieve in college, they pay more attention to things outside curriculums and they have confidence in the MOOC platform to achieve further self-improvement, so there are more people want to get more credits. When it comes to seniors in college, more and more people want to be more competitive in the future job hunting by gaining more credits and qualifications through MOOC, so they are thirsty for things outside curriculums to get themselves prepared for the coming employment interviews or the Unified National Graduate Entrance Examination, so they pay less attention on college courses. They start focusing on top-quality courses at close quarters, which can broaden their horizons and can help them make a decision on where they want to make a further study. In whole, at first most of them are not aware of the value of MOOC, and they attend it with weak motivations, but to students of senior age, they become more aware of the choice of MOOC and know clearly what they want from MOOC with none of them following suit

TABLE III

THE FACTORS AFFECTING MOOC LEARNING $\quad[\mathrm{N}=195, \mathrm{~N}(\%)]$

\begin{tabular}{llll}
\hline Factors Afftecting MOOC Learning & Much & A Little & No \\
\hline Less spare time & $71(36)$ & $108(55)$ & $16(9)$ \\
Deep loneliness of study online & $119(61)$ & $47(24)$ & $29(15)$ \\
Poor autonomous learning ability & $113(58)$ & $36(18)$ & $46(24)$ \\
Not so fruitful as expected & $127(65)$ & $59(30)$ & $9(5)$ \\
Weak pertinence of curriculum & $108(55)$ & $52(27)$ & $35(18)$ \\
\hline
\end{tabular}

The data in Table III tell us that the main reason for quitting MOOC is whether it is as fruitful as they expected, which means they attach great importance to the practical results of MOOC learning. The second factor that means a lot to their MOOC learning is the active learning atmosphere, in which they can communicate and exchange ideas in the process of learning, so most of them will quit MOOC for the poor interaction of it. Nearly $58 \%$ students will give up MOOC for the reason that they are not autonomous enough, because MOOC asks people for strong self-control in learning. 108 out of 195 students will quit MOOC for its lack of professional knowledge, most of senior students who are busy with internship, preparation for the postgraduate entrance examination, or job-hunting.

\section{DISCUSSION}

As an innovative form of online education, MOOC has a huge advantage over traditional classroom, which has been proved by the fact that it has promoted the overall educational quality and narrowed the gap of educational levels by freely sharing excellent educational resources within a larger scope. Like other online education forms, MOOC has broken through the space-time limitation of traditional teaching and learning, setting learners free from time and space. MOOC has functioned greatly in higher education of China, but there are still many problems that can't be ignored and should be solved as promptly as possible.

\section{A. Problems in the Construction of Online Resources and Its Solutions}

1. There is a lack of diversification and systematization in the contents of online resources and discipline system is incomplete. Most of online platforms feature courses of science and engineering, while a few with contents of humanities don't do well in specialization.

MOOC platforms should keep a balance between disciplines and make them specialized and humanized. Cooperative relations between universities should be established and strengthened to realize mutual complements in disciplines and online resources. Meanwhile, platforms should enhance the broader relevance and interactivity between disciplines, and online resources should be updated in time.

2. The scoring system is not reasonable and complete enough to be used to grade students. Due to the weak regulatory mechanisms, the problem of cheating in exams is severe. Some learners even communicate answers of test publicly online to get through the test, and even a large number of students meaninglessly copy and paste words post online by others to get the points of forum interaction, which will result into the failure in assessing learning efficiency.

A reasonable and scientific check-up system should be set up, and it can be different between different disciplines, and exam system should be established and completed. Technicians of platforms should improve relevant technique to help supervise learning and participating situation of learners, the result of which will be a part of final scores. The reasonable evaluation mode can be established by combining online learning with offline test. At the same time, we can adopt the experience of foreign countries for reference in authentication technology to guarantee the learning credibility of learners and make certificate of completion of MOOCs recognized on a larger scale.

3. Evaluation and feedback can't be conveyed to learners in time. The reliable and

Authentic evaluation and feedback can not only help learners gain the sense of achievement but also help to know the usage of resources. But usually learning effectiveness can't be examined and promoted in time, because questions of learners can't be answered promptly due to the shortage of teaching staff. 
If the shortage of teaching staff can't be solved in the short run, teachers can ask some students doing well in their studies to assist them to answer the questions of learners, and can encourage other learners online to offer their answers and reward them properly (not financially), which will help improve learners' motivations for learning and get teachers a little alleviated from work.

\section{B. Problems Affecting Learners' Learning Efficiency}

1. The motivation of learners for MOOC is not clear enough. According to the results of the questionnaire about motivations for MOOC learning, we can see that most of students have MOOC for the purpose of supplementing what've been learned in class, that's to say, most of them learn MOOC only to fulfill what their teachers ask them to learn, kind of learning passively and lacking initiative. Less fifty percent of students learn MOOC with the thirsty for knowledge itself, most of whom are seniors. There is even a few people attending MOOC for the curiosity about new things or just following suit. No wonder there is a high rate of registering every year, but a low rate of completion and a high rate of dropout of MOOC. It is unclear motivations that cause the great decrease in the numbers of learners three weeks later on average, which is also the main reason for the low learning efficiency (Huang Hao, Liu Zhi and He Xiangyang, 2015).

Before we start MOOC, we should introduce it to students systematically about its basic information, its structure, its function, and what students can achieve through it. Only by doing so, can most students gain the real motivations for MOOC and finish them with high learning efficiency.

2. Most students said that they couldn't feel the immersion and participation due to the poor interaction. Interaction includes two aspects: interaction between teachers and students, interaction between students. The fact their questions can't be answered in time or their questions are even seldom answered always frustrates them a lot. Due to that fact that most teachers can't spend long time in communicating and discussing with students, many problems can't be solved timely and efficiently, which definitely has a great effect on their enthusiasm for MOOC learning. According to the data about MOOC platform, most of learners never interact with others, and even those who have ever participated in interaction, often interact ineffectively, because there is nothing meaningful in their forum post only with the purpose of scoring from interaction (Li Zhengyan, 2015). Overall, both these two interactions are not satisfactory with small quantity and poor quality.

Teachers should guide positively in the interactive module, offer proper supervision and warnings for their online study, and answer their questions in time in order to enhance their sense of participation and to improve students ' initiative. Meanwhile, learners should be encouraged to interact with each other, even with others of other universities. Above all, the evaluation system of their interactive performance should be established and completed---both the quantity and the quality of interaction should be taken into consideration. What's more, there should be more ways of interaction, including interaction within a class, interaction between classes, interaction through a system called Danmu (real-time comments from viewers flying across the screen like bullets), etc. Effective interaction will make online education attractive and interesting.

\section{Difficulties Teachers Meeting in Making MOOC}

There is a strong demand for excellent teaching staff and technicians to take part in the construction and development of MOOC, but most of teachers are not willing to participate in it. There are some reasons: First, from learning how to produce a video to online interacting and data supervision, it often takes long time and lots of energy for teachers to make MOOC. Second, heavy teaching jobs and tremendous pressure of the task of scientific research prevent teachers from devoting themselves to MOOC; Third, the lack or the imperfection of necessary incentive doesn't work in motivating teachers to dedicate themselves to MOOC; Fourth, most colleges and universities are not completely aware of the fact that the construction MOOC can help them gain a high profile, so they take an indifferent attitude to teachers' participation of MOOC.

Some measures should be taken to deal with these difficulties. First, the construction of MOOC should be combined with daily teaching jobs efficiently. Teachers can use MOOC as a part of their flipped classroom teaching, and videos produced for MOOC platform can also be used in the classroom, which is a better way to reduce the time of preparation for daily teaching job and to ease the burden of daily teaching tasks. Second, college teachers at all levels should be encouraged to participate in MOOC. Competent authorities of colleges and universities should value the construction of MOOC, and actively organize, motivate and fund teachers to take part in it. For example, the construction of MOOCs can be one of requirements in college professional title evaluation. Third, MOOC platforms can inspire teachers to participate in MOOC by honoring them or entitling them to use platforms freely and with more access permissions.

\section{CONCLUSION}

It's true that MOOC, an innovative form of online education, has had a great effect on education in China and there are more and more MOOC courses, but there are still many problems that we can't ignore and we need to solve them promptly and effectively. Only when we know well its status quo, and only when we solve as many problems as we can, can MOOC platforms function perfectly both in higher and basic education in China. Educational reform will never stop all over the world, neither will it in China. The development of MOOC in China should be based on China's 
national conditions - its unique cultural background, its present educational conditions, and the habits of teaching and learning, etc---that can make the development of MOOC sustainable and steady.

\section{REFERENCES}

[1] Chen Yonggeng and Zhong Man. (2016). Analysis of the Current Situation of MOOC Platform for Basic Education in China. Education Modernization, Vol.19, 247-249.

[2] Huang Hao, Liu Zhi and He Xiangyang. (2015). Research On College Students' MOOC Learning Behavior. China Medical Education Technology, Vol.29, 601-606.

[3] Li Zhengyan. (2015). Problems and Solutions of the application of MOOC Platform----XuetangX As An Example. China Information Technology Education, Vol. 22, 111-115.

[4] Tang Ying. (2015). Analysis of the conditions to Localize MOOC Efficiently. China Adult Education, Vol.17, 152-155.

[5] Yu Xin, LU Hong-lei. (2014). Research on Influence Factors of Learners Adopting MOOC: Based on User Surveys of Qsinghua University's “Online School”. Modern Distance Education, Vol.5, 3-8.

Yuefang Sun, born in Jining, Shandong Province in 1979. She received the bachelor degree from Shandong Science and Technology University in 2002, and the master degree from Qufu Normal University in 2012.

She is currently a lecturer in School of Foreign Languages, Jining Medical University, Jining, China. She has been teaching in Jining Medical University for seventeen years; courses taught include Integrated English, and Traditional Chinese Cultures (English version); her research interests include Applied Linguistics and second language acquisition. 